\title{
4. Staatliche Organisierte Kriminalität
}

An dieser Stelle ist auch noch auf eine als „Staatlich Organisierte Kriminalität" zu bezeichnende Erscheinungsform hinzuweisen, die sich auf Länder bezieht, die sich auf ein „Unterlaufen“ von in anderen Ländern bestehenden nationalen Steuerverpflichtungen spezialisiert haben. Aufgrund ihrer Gesetzgebung werden sie zu Pools von sogenanntem „Schwarzgeld“ oder auch zur Geldanlage von versteuertem Einkommen um weitere Steuerbelastungen durch die Verzinsung dieses Kapitals zu vermeiden. Bekanntermaßen trifft dies in Europa sehr stark auf die Schweiz zu, wobei es internationale und nationale Bestrebungen gibt, diese Möglichkeiten durch Verträge zu verhindern. Weitere Länder, die Anlagemöglichkeiten für Kapitalvermögen bieten, tauchen kurzfristig immer wieder auf. Immer wieder werden jedoch Singapur, einige Karibische Inselstaaten aber auch die Kanalinseln in Europa genannt. Dabei darf jedoch der Blick nicht nur auf diese Länder gehen, sondern er muss auch Gesetzesinitiativen in Deutschland mit einschließen, wenn z. B. die amtierende Bundesjustizministerin, Leutheusser-Schnarrenberger, FDP, per Gesetz Ermittlungsbeschränkungen gegen Steuerhinterzieher festlegen lassen will (vgl. dazu Behörden Spiegel, 28. Jg., 36. Woche, S. 1).

Auch zu dieser Erscheinungsform fehlen bisher einschlägige kriminologische Untersuchungen, sodass an dieser Stelle nur ein Augenmerk auf diese Form staatlicher Unterstützung von delinquenten Handlungen zu richten ist. Hierdurch entstehen zahlreichen Nationalstaaten erhebliche Schäden, als Beispiel sei die Situation in Griechenland 2011 oder 2012 genannt. 